\title{
Ensino e aprendizagem como unidade dialética na atividade pedagógica
}

\author{
Maria Eliza Mattosinho Bernardes
}

\section{Resumo}

Considerar a atividade pedagógica como unidade dialética requer que sejam investigadas as condições e circunstâncias que tornam possível tal objetivação e as especificidades da mesma a partir do materialismo histórico dialético, da psicologia histórico-cultural e da teoria da atividade. Concebe-se que a correspondência entre motivos/necessidades, objetivos, ações e operações nas atividades principais dos estudantes e dos educadores cria situações favoráveis para que ocorra a aprendizagem consciente. Tal fato é dependente da consciência da função ontológica do educador e do estudante como sujeitos ativos no processo de ensino-aprendizagem. Considera-se ser possível conceber a unidade dialética desde que a mesma represente uma das condições para a superação das características do sistema educacional vigente, por caracterizar-se a atividade material do homem como a que transforma o mundo material e social em mundo humano.

Palavras-chave: Ensino, aprendizagem, dialética.

\section{Teaching and learning as a dialectical unity in pedagogical activity}

\begin{abstract}
In order to consider pedagogical activity as dialectical unity one needs to investigate the conditions and circumstances of her/his work. One also needs to research on its specifications from the perspective of the historical dialectical materialism approach, the historical cultural psychology and the activity theory. It is believed that the correspondence among need and aims, actions and operations in the students and educators' main activities create positive situations so that a conscious learning occurs. This fact depends on the educator's and the student's awareness of their ontological function in the teaching-learning process. It seems to be possible to conceive the dialectical unity. But it has to represent one of the conditions to overcoming the nowadays educational system. It is also necessary to conceive man's activity as one which transforms the material and social world into a human world.
\end{abstract}

Keywords: Teaching, learning, dialects.

\section{Enseñanza y aprendizaje como unidad dialéctica en la actividad pedagógica}

\section{Resumen}

Considerar la actividad pedagógica como unidad dialéctica requiere que sean investigadas las condiciones y circunstancias que hacen posible tal objetivación y las especificidades de la misma a partir del materialismo histórico dialéctico, de la psicología histórico-cultural y de la teoría de la actividad. Se concibe que la correspondencia entre motivos/necesidades, objetivos y acciones y operaciones en las actividades principales de los estudiantes y de los educadores crea situaciones favorables para que ocurra el aprendizaje consciente. Tal hecho es dependiente de la consciencia de la función ontológica del educador y del estudiante como sujetos activos en el proceso de enseñanza-aprendizaje. Se considera posible concebir la unidad dialéctica desde que la misma represente una de las condiciones para la superación de las características del sistema educativo vigente, por caracterizarse la actividad material del hombre como la que transforma el mundo material y social en el mundo humano.

Palabras-clave: Enseñanza, aprendizaje, dialéctica. 


\section{Introdução}

O presente texto apresenta um estudo teórico sobre a identificação das condições e circunstâncias que possibilitam a integração das ações de ensino e aprendizagem no contexto escolar. Torna-se necessário, portanto, explicitar em termos gerais como e de que forma o homem, como ser genérico, por meio das relações sociais, apropria-se do conhecimento, cria novas possibilidades de transformação da sua própria constituição e da sociedade. Considerar a dimensão ontológica da constituição do ser humano, que se estabelece por meio da atividade educativa, vincula-se ao conceito de práxis. Tal conceituação, segundo Vázquez (1977, p. 3), deve ser entendida "como atividade material do homem que transforma o mundo natural e social para fazer dele um mundo humano".

Na relação entre o ensino e a aprendizagem, como instrumento e produto da atividade educativa em geral, concebe-se, a partir do referencial teórico do materialismo histórico-dialético, da psicologia histórico-cultural e da teoria da atividade, a existência de atividades humanas particulares. Uma dessas atividades, segundo Moura (1996), é a atividade de ensino que tem a função particular de organizar ações que possibilitem aos sujeitos o acesso aos conhecimentos elaborados socio-historicamente.

Tais ações, no contexto escolar, referem-seàs ações do educador que organiza o ensino com a finalidade de promover a humanização dos indivíduos por meio da aprendizagem do conhecimento historicamente elaborado (no contexto escolar). O produto do ensino, consequentemente, pode ser entendido como a apropriação do conhecimento científico por meio de ações dos estudantes que lhes possibilitem fazer uso de tais conceitos nas diversas relações com a realidade objetiva, tanto na sua manifestação externa - nas relações interpessoais - quanto na sua manifestação interna - nas relações intrapessoais. A apropriação do conhecimento promove mudanças qualitativas no psiquismo de quem aprende por possibilitar que o estudante estabeleça novas relações com o mundo objetivo (Leontiev, 1994; Vygotsky, $1994,2000,2001)$. O movimento de mudanças qualitativas das funções psíquicas superiores indica a transformação das condições próprias dos estudantes.

No entanto, a transformação do psiquismo somente pode superar as condições ingênua e espontânea decorrentes das relações imediatas do cotidiano mediante ações educacionais sistematizadas e conscientes que considerem as necessidades do desenvolvimento humano. Assim, as ações presentes na atividade de ensino não podem ser descoladas das condições necessárias para que ocorra a concretização da dimensão ontogenética na constituição dos indivíduos. Se ocorrer, fica caracterizado o distanciamento entre a condição necessária para o desenvolvimento humano e a ação mediadora que atua como instrumento que busca garantir, por meio da atividade de ensino, a constituição do gênero humano. Nestas condições, a atividade de ensino, executada conscientemente e com a finalidade de promover a transformação no processo de humanização dos estudantes, determina os seus meios - as ações e operações realizadas na prática pedagógica.

A atuação prática material do sujeito, executada de forma consciente sobre a realidade natural ou humana, transformando-a, é identificada por Vázquez (1977) como práxis. Assim, o produto dessa atividade prática deve ser objetivado materialmente na constituição da nova realidade.

A partir de tais considerações, concebe-se que a práxis é uma atividade humana consciente que se diferencia da atuação prática desvinculada de uma finalidade e apresenta um produto final que se objetiva materialmente. Trata-se de uma atividade orientada por um fim que, segundo Vázquez (1977), ocorre em dois níveis, ou seja, "essa atividade implica na intervenção da consciência, graças à qual o resultado existe duas vezes - e em tempos diferentes -: como resultado ideal e como produto real" (Vázquez, 1977, p. 187).

A extensão e o significado da categoria de práxis relacionados ao trabalho são explicitados por Jaroszewski (1980) ao identificar os elementos que constituem a estrutura do processo do trabalho humano como o contato material do homem com a natureza, as atividades orientadas e as qualificações práticas e os conhecimentos utilizados no curso da produção. O autor afirma que o resultado final desse processo "[...] é a criação dum novo 'produto'- quer dizer, dum objecto transformado pela actividade humana indispensável para satisfazer as necessidades do homem" (Jaroszewski, 1980, p. 9).

Sobre a atividade consciente realizada no movimento de transformação da realidade objetiva, natural ou humana, o autor afirma que a mesma surge do reconhecimento de uma necessidade e, para isso, requer a obtenção de informações sobre o objeto, o que determina a formulação do fim e do programa a ser realizado a partir de tomadas de decisões acerca das ações a serem realizadas no movimento de atuação no contexto específico. Tais aspectos da efetivação da atividade consciente ainda requerem que, nas ações orientadas por um fim, haja "o dispêndio, para além da energia psíquica, dum certo quantum de energia física que se integra no objeto, nele se condensando ao transformálo", como ainda requerem que ocorra "a adaptação do desenrolar das atividades à natureza e às especificidades objetivas do mundo exterior (matéria ou sociedade) que está a ser transformado" (Jaroszewski, 1980, p. 28). Nestas condições, o autor afirma não ser possível incluir, no conceito de "práticas", as atividades puramente teóricas, ou ainda outras formas de atividade conscientes que envolvam a reflexão sobre o mundo, em virtude da não objetivação na transformação da realidade, que ocorre somente na dimensão extraconsciente.

Vázquez (1977) também não identifica a atividade teórica como práxis por considerar que sua finalidade imediata é elaborar ou transformar idealmente e não materialmente o objeto da atividade. Os produtos dessa atividade são as teorias que explicam as relações entre o homem e o mundo objetivo, construindo modelos ideais a respeito da realidade futura. Este posicionamento é evidenciado ao conceber como práxis produtiva a que não só produz um mundo humano 
materializado, mas também aquela em que o homem se produz, forma ou transforma a si mesmo.

Tal reflexão tem como intenção relacionar as ações de ensino e as de aprendizagem na constituição da atividade pedagógica, não perdendo de vista a dimensão teóricoprática presente na atuação do educador, que se fundamenta na necessidade de humanização dos indivíduos, analisa a realidade e as condições postas a partir das informações e conhecimentos obtidos no contexto escolar, organiza objetivamente os meios de atuação, segundo a finalidade da educação, e atua de forma consciente para se materializar na construção do objeto da atividade de ensino.

Cabe, portanto, a reflexão sobre qual é objeto da atividade de ensino. Como esse objeto se materializa e em que dimensão é possível a sua materialização? Tais questões fazem com que se leve em conta a dupla objetivação da ação de ensinar.

A primeira objetivação, posta pela própria finalidade da educação escolar, é a constituição da dimensão do gênero humano originada na apropriação da produção humana elaborada socio-historicamente que promove a transformação e o desenvolvimento atual ou real dos indivíduos. Tal possibilidade é estabelecida de forma indireta na atuação profissional do educador na atividade de ensino quando atua conscientemente, direcionando suas ações para a transformação do sujeito que aprende - o primeiro objeto da atividade de ensino. Considera-se que o produto desta objetivação (a apropriação do conhecimento e a transformação psíquica dos estudantes e do próprio educador) é relativo, uma vez que não se pode ter controle sobre a sua materialidade. Porém, não se pode afirmar que tal produto da atividade de ensino não se objetive materialmente no desenvolvimento atual dos indivíduos, mesmo que o produto da atividade não seja pleno e sim, parcial.

Outra objetivação da ação de ensinar vincula-se diretamente à atuação profissional do educador. Refere-se ao conteúdo da atividade de ensino, ou seja, o que e de que forma se organiza o ensino - o segundo objeto. A seleção e a identificação do conhecimento teórico-científico a ser ensinado na escola e a definição das condições adequadas para a materialização da organização das ações de ensino na atividade pedagógica requerem que o educador materialize o segundo objeto da atividade de ensino. O produto desta atuação profissional é a elaboração de um instrumento que medeia o conhecimento que se objetiva e se materializa na organização das ações do ensino.

Concebe-se, portanto, que não se pode afirmar que a atividade pedagógica, aquela que sintetiza as ações de ensino e de aprendizagem como unidade, não seja práxis, uma vez que a materialização do produto da atividade orientada se faz como objeto real em duas dimensões: a) na dimensão psíquica do indivíduo que aprende e que ensina, objetivada no seu desenvolvimento real; b) na dimensão material da prática profissional do educador que constrói o instrumento que medeia o conhecimento, objetivado na organização do ensino.
Considera-se, desta forma, que a atividade pedagógica seja práxis, pois se expressa por meio da atividade teórico-prática executada pelo educador. Trata-se de uma particularidade da práxis, uma vez que a atividade pedagógica pode ser entendida como uma atividade coletiva que promove a transformação dos sujeitos, sejam eles considerados os grupos sociais ou os indivíduos singulares.

A dupla objetivação da atividade pedagógica evidencia a necessidade de se levar em conta a dimensão psicológica presente na relação entre o ensino e a aprendizagem e a dimensão pedagógica presente na atividade orientada para o ensino por meio da ação intencional e consciente do educador. A explicitação das duas dimensões presentes na objetivação e materialização da atividade pedagógica demonstra a necessidade de se conceber o processo de ensino e aprendizagem vinculado à psicologia e à pedagogia, as quais são áreas de conhecimento que compõem os caminhos para a compreensão e a efetivação da educação escolar. Não se trata da psicologização da pedagogia, nem da pedagogização da psicologia, mas trata-se da concepção de que a educação e a formação dos indivíduos, como pertencentes ao gênero humano, necessitam ser analisadas e definidas como unidades que integram a produção do conhecimento nas duas áreas epistêmicas.

A atuação consciente do educador, movida pelos fins que promovam a genericidade da constituição humana por meio da educação, é tratada por Saviani (2003) como o trabalho educativo. Tanto Duarte (2003) quanto Oliveira (1996) comentam a definição de trabalho educativo, inicialmente tratado por Saviani, e inserem tal categoria do trabalho como determinante da constituição do ser em devir.

Segundo Duarte (2003, p. 36-7), tal conceito assume a perspectiva de superação da concepção de essência humana abstrata e da existência empírica por conceber que a humanidade é produzida histórica e coletivamente pelos homens. Também afirma que "[...] supera a concepção de educação guiada pela existência empírica, na medida em que sua referência para a educação é a formação do indivíduo enquanto membro do gênero humano." Portanto, deve ser entendido como uma produção "direta e intencional", dirigida por fins que visam à constituição da dimensão humana dos indivíduos por meio da educação. A dimensão ontogenética do trabalho educativo também é salientada por Oliveira (1996, p. 21) ao afirmar que "[...] a educação concebida como atividade mediadora no seio da prática social global serve ao objetivo de 'promover o homem', isto é, tem o objetivo de possibilitar ao homem tornar-se cada vez mais um ser histórico-social consciente."

De acordo com Paro (2002), o educador exerce uma função especial na organização das ações educacionais quando se assume como devedor da classe social a que pertence. Afirma que "a escola estará contribuindo para a transformação social não apenas quando promove a transmissão do saber, mas [...] também quando consegue concorrer para o desenvolvimento da consciência crítica de sua clientela1." (Paro, 2002, p. 118-9). A consciência histórica,

1 Considera-se que o termo "clientela", conforme o uso na citação 
aliada à percepção da importância da representação da classe trabalhadora como instrumento da transformação social viabilizada pela educação escolar, é identificada pelo autor como "[...] a verdadeira dimensão revolucionária do trabalho pedagógico na escola." ( p. 118).

O que se identifica, a partir de tais reflexões, é que o trabalho do educador no contexto escolar deve ser direcionado por um fim, pela pertinência histórica da constituição humana e pela formação da consciência crítica dos estudantes. A consciência dos fins da educação escolar determina os meios pelos quais a ação pedagógica é realizada, ou seja, determina a atividade pedagógica a ser realizada na escola. No entanto, nem sempre as ações pedagógicas executadas pelos sujeitos na escola assumem a dimensão ontogenética, a que resgata tanto a historicidade dos conceitos quanto das funções a serem realizadas pelos mesmos. O que se verifica nas ações pedagógicas (na maioria das vezes) é a objetivação da dimensão imediata do conhecimento, considerando o uso do mesmo para as relações práticas exercitadas em sociedade (relação singular-particular na qual a particularidade substitui o universal).

Pode-se, no entanto, questionar se as ações realizadas pelos educadores, de forma consciente e intencionalmente planejadas, produzem o resultado esperado - a aprendizagem consciente ${ }^{2}$ dos estudantes. Entende-se que este produto também não pode ser garantido em virtude da complexidade posta na organização da sociedade capitalista contemporânea que, pelo processo de alienação, rompe com a unidade dialética presente no esquema instrumentoproduto, objetivamente expresso pela relação ensinoaprendizagem. No entanto, concebe-se que, se o produto não for efetivado, plenamente ou parcialmente, não se pode considerar o instrumento como um elemento mediador na produção dos objetos da atividade pedagógica.

A partir de tais pressupostos, cabe o seguinte questionamento: em que condições e circunstâncias se pode verificar a unidade presente entre as ações de ensino e as ações de aprendizagem? Como se estabelecem os motivos geradores das atividades particulares humanas relacionadas às ações de ensino e de aprendizagem de tal forma que possam ser identificados sinais que evidenciem a unidade esperada na atividade pedagógica? Assim, tornase necessário apresentar as ações e as operações na organização da atividade pedagógica que tornem possível a objetivação e a materialização do ensino e da aprendizagem como unidade dialética.

\section{A Atividade Pedagógica: Unidade entre o Ensino e a Aprendizagem}

Partindo da conceituação de que a atividade pedagógica seja uma particularidade da práxis que se

de Paro (2002), dentro dos pressupostos teórico-metodológicos do materialismo histórico dialético, refere-se ao conjunto de sujeitos em geral e aos estudantes em particular que se inserem no contexto escolar.

2 O termo aprendizagem consciente é utilizado inicialmente por Leontiev (1983), ao reportar-se à atuação do estudante na atividade de aprendizagem no contexto escolar. constitui numa atividade coletiva e transformadora das relações sociais originadas das relações educacionais no contexto escolar, concebe-se que a mesma sintetize as ações de ensino e aprendizagem como unidade dialética.

Asbahr (2005) elucida a significação da atividade pedagógica nos marcos do materialismo histórico dialético ao particularizar a dimensão educativa presente nas relações entre o ensino e a aprendizagem em geral tratadas pela psicologia histórico-cultural. Afirma que a escola é a instituição social que tem como finalidade a transmissão do saber historicamente acumulado de forma sistematizada e organizada. Considera que a significação social da atividade pedagógica realizada pelo professor é proporcionar condições de ensino que possibilitem aos estudantes engajarem-se em atividades de aprendizagem, garantindo-Ihes a apropriação do conhecimento não cotidiano.

Além de criar condições para que os estudantes se apropriem do conhecimento elaborado e de proporcionar situações que promovam o desenvolvimento psíquico, Asbahr (2005, p. 61) indica também como significação social da atividade pedagógica a:

[...] formação crítica do aluno, possibilitando que este tenha acesso também ao processo de produção do conhecimento. [...] [Assim], o aluno não é só objeto da atividade do professor, mas é principalmente sujeito e constitui-se como tal na atividade de ensino/aprendizagem na medida em que participa ativamente e intencionalmente do processo de apropriação do saber, superando o modo espontâneo e cotidiano do conhecer.

Tanto Leontiev (1978), ao analisar a ruptura entre o significado social e o sentido pessoal nas atividades humanas em geral, quanto Asbahr (2005), Duarte (2004), Marin (2003), Martins (2001), Serrão (2004) e ao analisarem o mesmo fenômeno referente à formação de professores e à particularidade da atividade pedagógica, afirmam que, quando não ocorre a correspondência entre o significado social e o sentido pessoal das ações na atividade pedagógica, esta se assume como uma atividade alienada.

Tal realidade descaracteriza a atividade pedagógica como uma particularidade da práxis que visa ao processo de transformação da própria sociedade por meio da transformação dos indivíduos, assumindo a configuração de ser, segundo Asbahr (2005), uma operação automatizada, ou ainda, um conjunto de ações que visam à ocupação do tempo designado ao processo de ensino e aprendizagem.

A transformação da sociedade por meio da transformação dos indivíduos, como um dos produtos da atividade pedagógica, deve ser entendida, na concepção dialética, como aquela que promove modificações nas circunstâncias e modificações no próprio homem de forma simultânea. Conforme afirma Vázquez (1977, p. 160), "[...] essa unidade entre circunstâncias e atividade humana, ou entre transformação das primeiras e autotransformações do homem, só se verifica em e pela prática revolucionária." A unidade dialética de transformação do homem e das circunstâncias é identificada pelo autor como práxis revolucionária. 
A atividade pedagógica, como práxis revolucionária, pressupõe que: "a) não só os homens são produtos das circunstâncias, como estas são igualmente produtos seus. [...]; b) os educadores também devem ser educados. [...]; c) as circunstâncias que modificam o homem são, ao mesmo tempo, modificadas por ele [...]". (Vázquez, 1977, p. 159160).

No que se refere ao homem como produto e sujeito das circunstâncias vinculadas ao contexto escolar, concebese que a constituição das funções psicológicas superiores do estudante não seja considerada meramente o produto moldável do processo de ensino, mas pressupõe que, no movimento de constituição de tais funções, também os estudantes sejam sujeitos tanto da sua formação quanto sejam influenciadores da organização de ensino a partir das suas características e necessidades, atuando como sujeito ativo na atividade pedagógica.

Os educadores também se educam durante a atividade pedagógica. Esse pressuposto tem como fundamento o lugar social do educador, que lhe atribui as funções de organizar o ensino, definir conteúdos e criar situações desencadeadoras da atividade de aprendizagem a serem realizadas pelos estudantes. Nesse processo coletivo de estudo e devido às mediações que promove, o próprio educador também é educado. Concebe-se, portanto, que, além dosconhecimentos que o educador deva ter apropriado acerca dos fundamentos teórico-metodológicos que definem as ações, os quais proporcionam transformações no psiquismo dos estudantes, e além dos conhecimentos que necessariamente precisa ter para ensinar os conteúdos escolares, o educador também se forme no movimento de organização do ensino. Por meio do processo reflexivo de elaboração da organização das ações orientadas para o ensino e a aprendizagem dos conteúdos escolares, o educador transforma-se, modificase, em virtude da necessidade de definir ações e operações na atividade pedagógica que possibilitem a concretização da aprendizagem por parte dos estudantes.

A respeito de as circunstâncias modificarem o homem e, ao mesmo tempo, de serem modificadas por ele, concebese que a constituição das relações sociais e econômicas próprias da sociedade capitalista contemporânea relacionase diretamente com a forma como o sistema educacional vigente se estabelece. Assim, a condição alienadora posta na sociedade pela forma com que se organiza, para ser superada, necessita da instituição de práticas "revolucionárias" que promovam a transformação das condições iniciais. Uma das possibilidades de superação dessa realidade ocorre por meio do processo educacional através da organização consciente e intencional da atividade pedagógica que tem a possibilidade de promover a transformação dos sujeitos integrados a ela.

Considera-se, portanto, que a atividade pedagógica como práxis revolucionária seja uma das possibilidades de superação das condições alienadoras postas pela sociedade capitalista contemporânea por meio da aproximação entre o sentido e o significado das atividades humanas caracterizadas no processo educacional escolar, a partir da atuação crítica e consciente dos sujeitos.
Entende-se que a atividade pedagógica concebida como práxis requer que educadores e estudantes estejam em atividade em comum (Rubtsov, 1996), com finalidades correspondentes, manifestas nas ações e operações realizadas pelo educador na atividade de ensino e pelos estudantes na atividade de aprendizagem. As ações e operações que compõem tal atividade envolvem a repartição dos modos de ação entre participantes envolvidos no processo de ensino e aprendizagem.

Ao propor, como elementos que compõem a atividade em comum, a repartição das ações e das operações, a troca dos modos de ação, a compreensão mútua por meio da comunicação, o planejamento das ações individuais em busca de resultados comuns obtidos pelo processo de reflexão, entende-se que seja possível a superação da individualidade dos sujeitos envolvidos na atividade orientada para o ensino e aprendizagem. Pressupõe-se, na atividade pedagógica, um produto coletivo elaborado por meio de ações e operações realizadas de forma cooperativa pelos sujeitos no processo de ensino e aprendizagem estudantes e educador.

No caso da atividade de ensino, o motivo é determinado pela necessidade de o educador ensinar o conhecimento teórico-científico elaborado socio-historicamente, promovendoahumanizaçãoeatransformação dos estudantes por meio de ações conscientes e intencionais definidas na organização do ensino. Na atividade de aprendizagem, o motivo é definido pela necessidade de o estudante se apropriar do conhecimento socio-histórico, tornando-se herdeiro da cultura, humanizando-se. Tanto na atividade de ensino quanto na atividade de aprendizagem, o motivo e o objetivo correspondem à necessidade de humanização dos indivíduos na relação com o gênero humano.

Para que ocorra a correspondência desejada entre as atividades particulares, os sujeitos realizam ações e operações próprias da atividade em que estão inseridos. As ações e operações do educador definem a organização do ensino que determina o conhecimento a ser ensinado e estabelece as condições mediadoras para que os estudantes venham a ter motivos para se integrarem na atividade de aprendizagem. As ações e as operações a serem executadas pelos estudantes na atividade de aprendizagem são correspondentes às expectativas presentes na organização do ensino. Tais ações e operações, segundo Davidov (1988), referem-se às tarefas de estudo, às ações de estudo e às ações de controle e avaliação das próprias elaborações dos sujeitos no movimento de apropriação dos conhecimentos socio-históricos.

$\mathrm{Na}$ organização do ensino que tenha como finalidade o desenvolvimento das funções psicológicas superiores dos estudantes, as ações e operações realizadas pelo educador na definição dos conteúdos de ensino requerem que sejam levadas em conta não somente os conhecimentos que representem os acontecimentos atuais nos diferentes aspectos da cultura ou a apropriação de técnicas para o uso imediato do conhecimento, mas torna-se necessário que sejam resgatados também os processos históricos de 
elaboração dos conceitos teórico-científicos. A análise da essência do conhecimento socio-histórico é preponderante para que os estudantes apropriem-se das elaborações materiais e ideais sem as quais não é possível a superação da condição empírica e espontânea proporcionada pela socialidade presente nas relações entre os indivíduos e a sociedade fragmentada no processo da alienação.

Ainda dentro da perspectiva da organização do ensino, cabe ao educador definir, seja individualmente ou coletivamente, os modos de ações que determinam as condições de mediação do conhecimento no contexto escolar. Os modos de ação na organização do ensino determinam as condições físicas em que o conhecimento é mediado, as formas das relações interpessoais realizadas entre professor e estudantes e entre estudantes, e a forma como o conhecimento é posto em movimento de reflexão entre os sujeitos da atividade pedagógica.

Quanto às ações e operações a serem realizadas pelos estudantes na atividade de aprendizagem, concebese que, pela forma como o conhecimento é posto em movimento nas relações de ensino e aprendizagem, tornase necessário que os estudantes realizem coisas, executem técnicas e procedimentos adequados às necessidades próprias para cada conteúdo em ação. Trata-se de tarefas de estudos como leitura, interpretação e construção de textos, cálculos, levantamentos bibliográficos, resolução de problemas práticos e teóricos vinculados ao conteúdo escolar a ser mediado na atividade pedagógica. Tais tarefas de estudo, segundo Davidov (1988), levam o estudante a dominar relações gerais acerca do conhecimento estudado e a dominar novos procedimentos de ação. Essas tarefas assumem diferentes dimensões quanto à forma como são encaminhadas nas ações orientadas para o ensino de conceitos.
Cabe aos estudantes, numa condição diferenciada da anterior, realizar ações de estudo que superem as relações gerais com o conhecimento. Tais ações identificam os princípios centrais do mesmo, ou seja, a essência do conhecimento; identificam modelos que expressam relações entre conceitos teóricos e possibilitam que o domínio de determinados procedimentos e conhecimentos apropriados anteriormente seja instrumento para a concretização de novas elaborações teóricas. Trata-se de ações e operações realizadas pelos estudantes que priorizam as relações reflexivas, mediadas por conhecimentos apropriados anteriormente, na (re)elaboração de conhecimentos pelos próprios estudantes na atividade de aprendizagem.

No movimento de apropriação do conhecimento na atividade de aprendizagem, os estudantes também realizam as ações de controle e avaliação que, pelo processo de explicitação das suas elaborações e de análise e crítica das elaborações pessoais e coletivas, possibilitam aos estudantes (re)elaborarem suas próprias concepções, superando-as consecutivamente. Trata-se de ações de autocontrole das elaborações realizadas pelos próprios estudantes que possibilitam a ampliação da capacidade de pensar reflexivamente pelo processo de análise e síntese das elaborações individuais e coletivas.

O quadro a seguir sintetiza as aproximações e correspondências entre a atividade de ensino e a atividade de aprendizagem, identificando a unidade presente na atividade pedagógica.

A correspondência entre as finalidades, os motivos, os objetivos e as ações e operações presentes na atividade de ensino e na atividade de aprendizagem não ocorre de forma natural ou espontânea no processo escolar. A correspondência entre as atividades particulares do educador e do estudante somente se torna possível quando os sujeitos envolvidos no processo têm consciência do lugar social que ocupam na organização das sociedades letradas.

QUADRO 1 - A unidade da atividade pedagógica

\begin{tabular}{|c|c|c|c|}
\hline & \multicolumn{2}{|c|}{$\begin{array}{l}\text { ATIVIDADE DE ENSINO - } \\
\text { Educador }\end{array}$} & $\begin{array}{l}\text { ATIVIDADE DE APRENDIZA- } \\
\text { GEM- } \\
\text { Estudante }\end{array}$ \\
\hline$\square$ MOTIVO/ NECESSIDADE & \multicolumn{2}{|c|}{$\begin{array}{l}\square \text { Possibilitar a transformação da constituição } \\
\text { dos estudantes por meio do acesso à cultura - } \\
\text { humanizando-os. }\end{array}$} & $\begin{array}{l}\square \text { Tornar-se herdeiro da cultura - } \\
\text { humanizar-se. }\end{array}$ \\
\hline$\square$ OBJETIVO & \multicolumn{2}{|c|}{$\square$ Ensinar o conhecimento socio-histórico. } & $\begin{array}{l}\square \text { Apropriar-se do conhecimento } \\
\text { socio-histórico. }\end{array}$ \\
\hline \multirow[b]{2}{*}{$\square$ AÇÕES E OPERAÇÕES } & \multirow[b]{2}{*}{$\begin{array}{l}\square \text { Organizar o } \\
\text { ensino: }\end{array}$} & $\begin{array}{l}\square \text { Definindo o conhecimen- } \\
\text { to a ser ensinado. }\end{array}$ & \multirow{2}{*}{$\begin{array}{l}\square \text { Executar tarefas de estudo; } \\
\square \text { Realizar ações de estudo; } \\
\square \text { Participar de ações de controle } \\
\text { e de avaliação. }\end{array}$} \\
\hline & & $\begin{array}{l}\square \text { Definindo as condições } \\
\text { (modos de ação) em que } \\
\text { o conhecimento será } \\
\text { ensinado. }\end{array}$ & \\
\hline
\end{tabular}

Fonte: Elaboração da autora 
A consciência do lugar social (Leontiev, 1994) ocupado pelo educador e pelo estudante é constituída pela correlação entre a significação social das ações realizadas e pelo sentido da atividade para os sujeitos pertencentes à coletividade.

Na sociedade capitalista contemporânea, a correlação entre o sentido e a significação das ações nas atividades humanas em geral é fragmentada, uma vez que, pelas condições postas no processo de alienação, os indivíduos raramente se apropriam das significações elaboradas no processo socio-histórico de constituição do gênero humano. Além disso, o sentido que as ações têm para os indivíduos é determinado pelos seus interesses pessoais, desconectados das necessidades e relações sociais produzidas pela coletividade a que pertencem.

No caso da atividade pedagógica, a relação entre a significação das funções sociais e o sentido das atividades particulares próprio do educador e do estudante também se encontra fragmentada na sociedade atual. Tal fato é evidenciado no cotidiano do contexto escolar diante das dificuldades vivenciadas na escola em geral.

O significado do lugar social do educador na atividade pedagógica é atribuído ao conteúdo histórico de suas ações, ao que ele faz na execução da atividade em que está inserido, ou seja, ao ato de ensinar os conceitos teóricos e outros elementos da cultura letrada que superam as relações presentes na apropriação dos conceitos espontâneos postos nas relações humanas em geral. A significação do lugar social do estudante na atividade pedagógica referese à atuação de estudo, a qual se espera do mesmo no movimento de apropriação dos conhecimentos teóricocientíficos produzidos historicamente para que o mesmo se constitua como herdeiro da cultura e possa intervir sobre a mesma. Se o sentido pessoal da ação, tanto do educador quanto do estudante, não corresponder à significação da ação elaborada historicamente, as atividades particulares constituintes da atividade pedagógica são consideradas alienadas.

No caso do educador, o sentido pessoal de sua atividade torna-se correspondente ao significado social de sua ação no movimento de formação profissional, no que se refere à formação inicial e à formação em exercício. É no processo de formação, ao assumir a posição de estudante, que o educador se apropria dos conteúdos da sua atividade principal, a atividade orientada para o ensino e aprendizagem dos conteúdos escolares. A constituição da consciência do lugar social do educador é desenvolvida na coletividade, no processo de integração a uma classe produtiva que tem finalidades instituídas na sociedade letrada. É por meio do trabalho coletivo na escola, do processo de estudo compartilhado, da luta de classe e da representatividade dos interesses educacionais na sociedade letrada que o educador assume níveis mais claros e mais desenvolvidos de consciência sobre o seu lugar social como representante de uma classe de trabalhadores que detém a possibilidade de transformação da sociedade por meio do desenvolvimento da consciência dos indivíduos com que se relaciona no seu contexto de trabalho - a consciência dos estudantes.

No caso do estudante, o sentido pessoal da sua função somente pode ser relacionado ao significado social da ação como estudante pelo processo educacional decorrente das relações interpessoais possibilitadas pela família e pela escola. A consciência do lugar social do estudante deve ser objeto da atividade educacional em geral, uma vez que a aprendizagem das relações humanas em sociedade não é espontânea, mas é decorrente da atividade orientada para o ensino de determinado conteúdo.

\section{Considerações Finais}

A constituição de consciência deve ser considerada objeto central das ações pedagógicas na escola, pois, para que seja possível obter a unidade entre as ações de ensino e aprendizagem, tanto o professor quanto o estudante devem ser conscientes do seu lugar social e de suas funções ontológicas.

Leontiev (1983), ao se referir ao sentido do estudo para a criança que compreende a necessidade e os motivos reais do mesmo, afirma que "[...] o sentido que adquire para a criança o objeto de suas ações didáticas, o objeto de seu estudo, é determinado pelos motivos de sua atividade didática. Este sentido também caracteriza a aprendizagem consciente de conhecimentos pela criança" (p. 246). No entanto, o autor considera não ser suficiente a apropriação da significação do objeto de estudo; é necessário educar o estudante para que ele perceba a "reprodução" do objeto de estudo numa "relação adequada" a respeito do que é estudado; tal relação pode ser possibilitada por situações em que o estudante se aproprie das relações presentes no processo de elaboração do próprio conhecimento. De acordo com Leontiev (1983, p. 246), "somente assim se satisfaz essa condição [aprendizagem consciente], os conhecimentos adquiridos se converterão para ele [o estudante] em conhecimentos vivos, serão 'órgãos de sua individualidade' genuínos e, em seu tempo, determinarão sua relação a respeito do mundo".

A aprendizagem consciente requer que as ações dos estudantes sejam mobilizadas pela relação entre o significado e o sentido da atividade de aprendizagem, além da necessidade de considerar as relações internas e externas presentes na elaboração do objeto de estudo. Devese considerar os nexos internos do conceito elaborados ao longo da historicidade do mesmo, assim como se deve levar em conta as conexões que o mesmo tem com as relações humanas em geral. Afirma-se que é a partir deste processo de apropriação das elaborações humanas constituídas socio-historicamente - os conceitos - que se torna possível a transformação da constituição objetiva e subjetiva dos indivíduos, crianças e estudantes em geral.

A organização do ensino que possibilite a criação de condições adequadas para que ocorra a aprendizagem consciente por parte dos estudantes é preponderante para que a finalidade da atividade pedagógica se objetive 
no processo de ensino e aprendizagem. A objetivação da relação entre o motivo e o objetivo da atividade pedagógica por meio das ações e operações realizadas pelo educador e pelo estudante é identificada, segundo os diversos autores do enfoque histórico-cultural, como a atividade orientada para o ensino e a aprendizagem.

\section{Referências}

Asbahr, F. da S. F. (2005). Sentido pessoal e projeto político pedagógico: Análise da atividade pedagógica a partir da psicologia histórico-cultural. Dissertação de Mestrado, Universidade de São Paulo, São Paulo.

Davidov, V. V. (1988). La enseñanza escolar y el desarrollo psíquico: investigación psicológica teórica y experimental. Moscou: Progresso.

Duarte, N. (2003). Sociedade do conhecimento ou sociedade das ilusões?: quatro ensaios crítico-dialéticos em filosofia da educação. Campinas, SP: Autores Associados.

Duarte, N. (2004). Formação do indivíduo, consciência e alienação: o ser humano na psicologia de A. N. Leontiev. Caderno CEDES, 24(62), 44-63.

Jaroszewski, T. (1980). M. Extensão e significação da categoria de práxis. Em V. de Magalhães-Vilhena, Práxis: a categoria materialista de prática social (Vol. II, pp. 9-37). Lisboa: Livros Horizontes.

Leontiev, A. N. (1978). O desenvolvimento do psiquismo. Lisboa: Horizonte Universitário.

Leontiev, A. N. (1983). Actividad, conciencia, personalidade. Havana: Pueblo y Educación.

Leontiev, A. N. (1994). Uma contribuição à teoria do desenvolvimento da psique infantil. Em L. S. Vigotski, A. R. Luria \& A. N. Leontiev, Linguagem, desenvolvimento e aprendizagem (5a ed.). São Paulo: İcone.
Marin, A. J. (2003). Formação de professores: novas identidades, consciência e subjetividade. Em E. F. A. Tiballi \& S. M. Chaves, Concepções e práticas em formação de professores: diferentes olhares. Rio de Janeiro: DP\&A.

Martins, L. M. (2001). Análise sócio-histórica do processo de personalização de professores. Tese de Doutorado, Universidade Estadual Paulista, Marília, São Paulo.

Moura, M. O. de. (1996). A atividade de ensino como unidade formadora. Bolema, 12, 29-43.

Oliveira, B. (1996). O trabalho educativo: reflexões sobre paradigmas e problemas do pensamento pedagógico brasileiro. Campinas, SP: Autores Associados.

Paro, V. H. (2002). Administração escolar: introdução crítica (11a ed.). São Paulo: Cortez.

Rubtsov, V. A. (1996). A atividade de aprendizado e os problemas referentes à formação do pensamento teórico dos escolares. Em C. Garnier, N. Bernarz \& I. Ulanovskaya, Após Vygotsky e Piaget: perspectivas social e construtivista escolas russa e ocidental (pp. 129-137). Porto Alegre: Artes Médicas.

Saviani, D. (2003). Pedagogia histórico-crítica (8a ed.). Campinas, SP: Autores Asociados.

Serrão, M. I. B. (2004). Estudantes de pedagogia e a "atividade de aprendizagem"do ensino em formação. Tese de Doutorado, Universidade de São Paulo, São Paulo.

Vázquez, A. S. (1977). Filosofia da práxis (2a ed.). Rio de Janeiro: Paz e Terra.

Vygotski, L. S. (1994). Aprendizagem e desenvolvimento intelectual na idade escolar. Em L. S. Vigotskii, A. R. Luria \& A. N. Leontiev. Linguagem, desenvolvimento e aprendizagem (5a ed.). São Paulo: İ́cone.

Vygotski, L. S. (2000). Pensamento e linguagem (2a ed.). São Paulo: Martins Fontes.

Vygotski, L. S. (2001). Obras escogidas. Madrid: Machado Libros.

\section{Sobre a autora}

Maria Eliza Mattosinho Bernardes (memberna@usp.br)

Universidade de São Paulo - Escola de Artes Ciências e Humanidades

\section{Correspondência}

Escola de Artes, Ciências e Humanidades Universidade de São Paulo Rua Arlindo Béttio, 1000 - Ermelino Matarazzo

CEP: 03828-000 